\title{
Non-stationarity of the signal and noise characteristics of seasonal precipitation anomalies
}

\author{
Ian M. Ferguson • Philip B. Duffy • \\ Thomas J. Phillips $\cdot$ Xu Liang $\cdot$ John A. Dracup • \\ Siegfried Schubert $\cdot$ Philip Pegion
}

Received: 30 June 2009/ Accepted: 15 May 2010/Published online: 8 June 2010

(C) The Author(s) 2010. This article is published with open access at Springerlink.com

\begin{abstract}
In order to improve seasonal-to-interannual precipitation forecasts and their application by decision makers, there is a clear need to understand when, where, and to what extent seasonal precipitation anomalies are driven by potentially predictable surface-atmosphere interactions versus to chaotic interannual atmospheric
\end{abstract}

I. M. Ferguson ( $\square)$

Department of Geology and Geological Engineering,

Colorado School of Mines, Golden, CO, USA

e-mail: imfergus@mines.edu

P. B. Duffy

Climate Central, Inc., Palo Alto, CA, USA

e-mail: pduffy@climatecentral.org

\section{T. J. Phillips}

Program for Climate Model Diagnostics and Intercomparison, Lawrence Livermore National Laboratory, Livermore, CA, USA e-mail: phillips14@1lnl.gov

\section{Liang}

Department of Civil and Environmental Engineering,

University of Pittsburgh, Pittsburgh, PA, USA

e-mail: xuliang@engr.pitt.edu

\section{J. A. Dracup}

Department of Civil and Environmental Engineering,

University of California, Berkeley, CA, USA

e-mail: dracup@ce.berkeley.edu

\section{S. Schubert}

Global Modeling and Assimilation Office, National Aeronautics and Space Administration, Goddard Space Flight Center, Greenbelt, MD, USA

e-mail: siegfried.d.schubert@nasa.gov

\section{P. Pegion}

Earth Systems Research Laboratory, National Oceanic and Atmospheric Administration, Boulder, CO, USA

e-mail: Phillip.Pegion@noaa.gov dynamics. Using a simple Monte Carlo approach, interannual variability and linear trends in the SST-forced signal and potential predictability of boreal winter precipitation anomalies is examined in an ensemble of twentieth century AGCM simulations. Signal and potential predictability are shown to be non-stationary over more than $80 \%$ of the globe, while chaotic noise is shown to be stationary over most of the globe. Correlation analysis with respect to magnitudes of the four leading modes of global SST variability suggests that interannual variability and trends in signal and potential predictability over $35 \%$ of the globe is associated with ENSO-related SST variability; signal and potential predictability are not significantly associated with SST modes characterized by a global SST trend, North Atlantic SST variability, and North Pacific SST variability, respectively. Results suggest that mechanisms other than SST variability contribute to the non-stationarity of signal and noise characteristics of hydroclimatic variability over mid- and high-latitude regions.

\section{Introduction}

It is well established that anomalous boundary conditions-most notably sea surface temperature (SST) anomalies-drive anomalous surface-atmosphere fluxes of sensible heat, latent heat, and momentum, which subsequently influence large-scale atmospheric circulation and moisture transport and thus contribute to hydroclimatic variability over much of the globe. While the persistence of internal atmospheric perturbations, including individual weather systems, is generally on the order of days to weeks (Lorenz 1963; Palmer 2000; Reichlerand and Roads 2003), SST anomalies may persist from seasons to years and influence weather and climate on these timescales 
(e.g. Hoerling and Kumar 2003; Schubert et al. 2004; Seager et al. 2005; Barnston et al. 2005; Quan et al. 2006). Ocean-atmosphere teleconnections, including the El NiñoSouthern oscillation (ENSO), Pacific decadal oscillation (PDO), and Atlantic multidecadal oscillation (AMO), are thus a significant driver of hydroclimatic variability on seasonal-to-interannual timescales (e.g. Stockdale et al. 1998; Koster et al. 2000; Schubert et al. 2004; Barnston et al. 2005; Saha et al. 2006; Schubert et al. 2007; Livezey and Timofeyeva 2008).

Recent studies have shown that the influence of oceanatmosphere teleconnections on hydroclimatic variability is non-stationary. For example, the influence of ENSO-related SST anomalies on seasonal precipitation over the continental United States exhibits significant interdecadal variability, which has been attributed to the modulating influence of North Pacific SST anomalies associated with the Pacific decadal oscillation (PDO) (Gershunov and Barnett 1998; McCabe and Dettinger 1999). Similarly, analysis of precipitation and streamflow forecast and hindcast skill has shown interannual and interdecadal variability in skill associated with ENSO, PDO, and other ocean-atmosphere teleconnections (e.g. Hamlet and Lettenmaier 1999; Schlosser and Kirtman 2005; Grimm et al. 2006). These results suggest that the physical mechanisms governing seasonal precipitation anomalies vary in time.

An improved understanding of the SST-forced potential predictability of seasonal precipitation anomalies-i.e. the degree to which seasonal anomalies are driven by a potentially predictable response to ocean-atmosphere forcing as opposed to chaotic atmospheric dynamics-is necessary to improve both seasonal precipitation forecasts and their application to real-world decisions (e.g. Shukla et al. 2000; Barnston et al. 2005). Numerous studies have used ensembles of atmospheric general circulation model (AGCM) simulations to characterize the SST-forced signal component, chaotic noise component, and potential predictability of seasonal precipitation anomalies. Interannual variability of signal and potential predictability have been largely attributed ENSO, with both exhibiting increases over much of the globe during ENSO events compared to ENSO-neutral periods (e.g. Brankovic et al. 1994; Kumar and Hoerling 1998; Pegion et al. 2000; Peng et al. 2000; Zwiers et al. 2000; Phillips 2006; Schlosser and Kirtman 2005; Wu and Kirtman 2006). More recently, Nakaegawa et al. (2004) showed a widespread positive trend in the potential predictability of $500 \mathrm{hPa}$ geopotential heights during boreal winter from 1950-2000, and Kang et al. (2006) showed positive trends in the leading principal components of the signal variance and potential predictability of boreal winter precipitation and temperature over the twentieth century. Both studies again attribute positive trends to an increase in the variance of ENSO-related tropical Pacific SST anomalies.

This study addresses two primary questions: are interannual variability and long-term trends in the SST-forced signal, chaotic noise, and potential predictability of seasonal precipitation anomalies statistically significant? And to what degree are they explained by variability and trends in the dominant modes of SST boundary conditions? We use a 14-member ensemble of twentieth century (19022001) AGCM simulations to decompose the signal and noise components of seasonal precipitation variability. Using a simple Monte Carlo approach, we evaluate the statistical significance of interannual variability and longterm trends in signal, noise, and potential predictability at each model grid cell against a null hypothesis of stationarity. We then use a similar approach to evaluate temporal relationships between signal and noise and the four leading modes of SST variability, including a global ENSO mode. Our results suggest that ENSO-related SST variability is the leading driver of non-stationarity in signal and potential predictability throughout the tropics, while non-stationarity over mid- and high-latitudes is not significantly associated with dominant modes of SST variability.

\section{Data and methods}

\subsection{Model and data}

We analyze a 14-member ensemble of twentieth century simulations (1902-2001) carried out with version 1 of the National Aeronautics and Space Administration (NASA) Seasonal-to-Interannual Prediction Project (NSIPP-1) AGCM. NSIPP-1 is a grid point model with a finite difference dynamical core (Suarez and Takacs 1995). A simple $\mathrm{K}$ scheme calculates turbulent diffusivities for heat and momentum in the boundary layer based on Monin-Obukov similarity theory, and convection is parameterized using the relaxed Arakawa-Schubert scheme. Land surface processes are represented by the Mosaic land surface model, with vegetation parameters described by a climatological cycle as detailed in Koster and Suarez (1996). Details of the model formulation and its climate are described in Bacmeister et al. (2000).

The simulations evaluated here were carried out as part of the climate of the twentieth century project (Folland et al. 2002). All simulations were forced with identical SST boundary conditions; ensemble members differ only in their atmospheric initial conditions, which were slightly perturbed in each case. SST boundary conditions were derived from the HadISST dataset (Rayner et al. 2003); land surface boundary conditions were calculated interactively by the Mosaic land surface model. For computational 
feasibility, simulations were run at a relatively coarse resolution of $3.0^{\circ}$ latitude by $3.75^{\circ}$ longitude with 34 unevenly distributed vertical levels. To limit potentially confounding influences, atmospheric $\mathrm{CO}_{2}$ concentration was held constant at $350 \mathrm{ppm}$ and solar insolation was prescribed as an annual cycle; however, global warming is represented to the extent that the twentieth century climate change signal is captured in the HadISST SST forcing dataset.

Our analysis focuses on the seasonal precipitation response to anomalous SST boundary forcing, which is predominately associated with SST-forced changes in large-scale circulation, including stationary waves, moisture transport, and storm tracks. NSIPP-1 was developed with particular emphasis on accurate simulation of tropical ocean-atmosphere interaction, mid-latitude stationary waves, and extratropical response to tropical SST anomalies. While the model does exhibit biases in the magnitude of seasonal means and variances, pattern correlation between seasonal mean precipitation fields from the simulations analyzed here and the global precipitation climatology project (GPCP) observational dataset (Adler et al. 2003; comparison limited to the period for which datasets overlap, 1979-2001) is 0.84 for December-JanuaryFebruary (DJF) and 0.79 for June-July-August (JJA); pattern correlation between simulated and observed variance fields is 0.82 for DJF and 0.73 for JJA. Spatial correlations are highly significant, suggesting that the model accurately simulates key features of the large-scale general circulation that govern the spatial distribution and seasonality of wet and dry zones.

More importantly for this study, NSIPP-1 reproduces the magnitude and spatial structure of observed teleconnections between tropical Pacific SST anomalies and seasonal precipitation over most of the globe. Correlations between Nino 3.4 SST anomalies and simulated seasonal precipitation anomalies are significantly different that observed over less than $15 \%$ of the globe for both DJF and JJA, and differences are not field significant (as per Livezey and Chen 1983). In addition, the ensemble analyzed here was previous evaluated by Schubert et al. $(2004,2008)$ and was shown to capture much of the low frequency precipitation variability over the US Great Plains, including the 'Dust Bowl' drought of the 1930s and severe drought of the 1950s. The ensemble analyzed here reproduces quite well salient features of observed seasonal precipitation, including dominant modes of interannual and low frequency variability.

The HadISST dataset used to derive prescribed SST boundary conditions was produced by the Met Office Hadley Center for Climate Prediction and Research using a twostage reduced-space optimal interpolation procedure followed by superposition of quality-improved gridded observations to restore local detail. SST near sea ice were estimated using statistical relationships between SST and sea ice concentration. HadISST provides spatially and temporally complete monthly SST fields on a $1^{\circ}$ by $1^{\circ}$ grid for the period from 1871 to the present. While HadISST compares well with previous global SST analyses, the early half of the record is reconstructed from sparse observations. In addition to potential data quality issues, the interpolation scheme used to reconstruct global SST fields results in spatial and temporal smoothing over data-sparse periods and regions (Rayner et al. 2003). Such errors in the SST forcing data likely impact early twentieth century climate in simulations analyzed here; the potential impact of damped SST on estimates of potential predictability is discussed in Sect. 5 .

While ocean-atmosphere forcing influences a number of atmospheric moisture and precipitation characteristics (e.g. Cayan et al. 1999; Randel et al. 2004; Santer et al. 2006), the current analysis focuses on seasonal precipitation anomalies. Seasonal-to-interannual precipitation variability impacts a broad range of all human and natural systems, and seasonal precipitation anomalies are one of the simplest and most widely used indices of hydroclimatic variability (e.g. Keyantash and Dracup 2002; Wilhite and Buchanan-Smith 2005; Phillips 2006; Garbrecht et al. 2006). For conciseness, we present results only for the boreal winter season (December-January-February, DJF); conclusions based on analysis of the boreal summer season (June-July-August, JJA) are similar and are therefore not discussed. Mean monthly precipitation was aggregated over DJF, and seasonal anomalies were calculated by removing the climatological average of the ensemble mean. Seasonal SST anomalies were calculated similarly from HadISST monthly SST fields.

\subsection{Definition of time-varying signal, noise, and potential predictability}

In theory, seasonal climate variability can be partitioned into a boundary-forced (signal) component and an internallygenerated (noise) component, and the potential predictability of seasonal anomalies can be quantified as the ratio of signal to noise (e.g. Madden 1976; Shukla 1983; Rowell 1998; Zwiers et al. 2000; Shukla 1998; Shukla et al. 2000). However, separating the signal and noise components of observed precipitation anomalies requires a priori assumptions of the statistical character of one or both components, which significantly influence subsequent estimates of potential predictability (e.g. Shukla 1983; Chervin 1986; Zheng et al. 2000). Moreover, observational studies are often limited by a lack of accurate and consistent observations over much of the globe (e.g. Rowell 1998; Koster et al. 2000; Barnston et al. 2005). We therefore quantify signal, noise, and potential predictability using an ensemble of 
AGCM simulations in which all simulations are forced with identical (prescribed) SST boundary conditions but started from different atmospheric initial conditions. Differences between ensemble members arise solely from chaotic sensitivity to initial conditions, whereas similarities are attributable to their common SST boundary forcing. SST-forced signal and chaotic noise can therefore be evaluated straightforwardly from the ensemble mean and intraensemble deviations, respectively (e.g. Zwiers 1996; Rowell 1998; Koster et al. 2000; Zwiers et al. 2000).

Let $x_{t n}$ denote the seasonal precipitation anomaly at a given grid cell for ensemble member $n$ and year $t$. For a given $n$ and $t, x_{t n}$ is the sum of an SST-forced signal component $\left\langle x_{t}\right\rangle$ that is common among all ensemble members and a chaotic noise component $x_{t n}^{\prime}$ that is unique to simulation $n$ :

$x_{t n}=\left\langle x_{t}\right\rangle+x_{t n}^{\prime}$

where angular brackets denote ensemble averaging and primes denote deviations from the ensemble mean. In an ensemble of simulations forced with identical SST boundary conditions, SST-forced signal $S_{t}$ at time $t$ can be estimated simply as magnitude of the ensemble mean $\left\langle x_{t}\right\rangle$, and chaotic noise $\boldsymbol{N}_{\boldsymbol{t}}$ at time $t$ can be estimated as the root mean square of the deviations $x_{t n}^{\prime}$ (e.g. Shukla et al. 2000; Barnston et al. 2005; Schubert et al. 2008):

$S_{t}=\left|\left\langle x_{t}\right\rangle\right|$

$N_{t}=\sqrt{\frac{1}{N} \sum\left(x_{t n}^{\prime}\right)^{2}}$

The potential predictability of seasonal precipitation anomaly at time $t$ based on ocean-atmosphere forcing is then given by the signal-to-noise ratio $S \boldsymbol{N} \boldsymbol{R}_{t}=S_{t} / \boldsymbol{N}_{\boldsymbol{t}}$.

The conceptual model used here is analogous to the oneway analysis of variance (ANOVA) model used in previous studies (e.g. Zwiers 1996; Rowell 1998; Koster et al. 2000; Zwiers et al. 2000); however, the form used here allows for analysis of temporal variability and trends in signal and noise characteristics (Schubert et al. 2008). It should be noted that in the model used here, variability associated with land-atmosphere feedbacks is not treated explicitly: where land-atmosphere feedbacks amplify the SST-forced signal (and are thus common to all ensemble members), they contribute to the signal component $\boldsymbol{S}_{\boldsymbol{t}}$; where feedbacks amplify chaotic variability (and are thus unique to a given simulation), they contribute to the noise component $\boldsymbol{N}_{\boldsymbol{t}}$.

\subsection{Variability and trends in signal, noise, and potential predictability}

In this study, we evaluate the statistical significance of means, interannual variability, and linear trends in the magnitudes of SST-forced signal, chaotic noise, and potential predictability of seasonal precipitation anomalies. Means are calculated as time averages over the simulation period; interannual variability is calculated as sample standard deviations, and linear trends are calculated as slopes of the linear regression between each variable and time:

$\bar{\theta}=\frac{1}{T} \sum \theta_{t}$

$\sigma_{\theta}=\sqrt{\frac{1}{T-1} \sum\left(\theta_{t}-\bar{\theta}\right)^{2}}$

$\beta_{\theta}=\frac{\sum\left(\theta_{t}-\bar{\theta}\right)\left(t-\frac{T+1}{2}\right)}{\sum\left(\theta_{t}-\bar{\theta}\right)^{2}}$

where $\theta$ represents the magnitude of a variable $S, N$, or $\boldsymbol{S N R} ; \bar{\theta}$ is the temporal mean of $\theta ; \sigma_{\theta}$ is its sample standard deviation; and $\beta_{\theta}$ is the linear trend in $\theta$ with respect to time.

\subsection{Spatiotemporal modes of SST variability}

Spatiotemporal modes of SST variability were calculated by principal component analysis (PCA). To avoid the problem of singularity in the SST covariance matrix, spatial eigenvectors (empirical orthogonal functions, EOFs) and their temporal expansion coefficients (principal components, PCs) were calculated by singular value decomposition of SST anomalies (Preisendorfer 1988; Saenz et al. 2002; Wall et al. 2003). SST anomalies were standardized prior to PCA, and high-latitudes (greater than $75^{\circ}$ ) were excluded. In addition to global modes of SST variability, relationships of signal and noise with PDO and AMO variability are also considered. PDO is defined as the leading EOF of North Pacific $\left(20^{\circ} \mathrm{N}-75^{\circ} \mathrm{N}\right)$ monthly SST variability after removing the global mean SST anomaly (Mantua and Hare 2002); AMO is defined as the areaweighted SST anomaly over the North Atlantic $\left(0^{\circ} \mathrm{N}-75^{\circ} \mathrm{N}\right.$; Enfield et al. 2001).

\subsection{Monte Carlo analysis}

Parametric hypothesis tests have been derived to evaluate the statistical significance of potential predictability as measured by SNR (Zwiers et al. 2000); however, parametric tests are not available to evaluate the significance of $\boldsymbol{S}$ and $\boldsymbol{N}$, or of variability and trends in $\boldsymbol{S}, \boldsymbol{N}$, and $\boldsymbol{S N R}$. Statistical significance was therefore assessed by Monte Carlo analysis. In general, the value of a given statistic is considered significant at a level $\alpha$ if the likelihood of obtaining that value "by chance" is less than $\alpha$; in the context of potential predictability, "by chance" would be 
in the absence of anomalous SST boundary forcing. Monte Carlo analysis was used to generate probability distributions of each statistic considered here for each grid cell and season; statistical significance was then assessed by comparing the value of each statistic to the 95th percentile of the associated Monte Carlo distribution. The null hypothesis of each test is therefore $\mathrm{H}_{\mathrm{o}}: \theta_{\text {ensemble }} \leq \mathrm{P}_{95}\left\{\theta_{\mathrm{MC}}\right\}$, where $\theta$ is a given statistic, $\theta_{\text {ensemble }}$ is its value calculated form the unperturbed ensemble, and $\mathrm{P}_{95}\left\{\theta_{\mathrm{MC}}\right\}$ is the 95th percentile of $\theta$ from the associated Monte Carlo distribution.

Two thousand Monte Carlo trials were carried out by randomly shuffling each ensemble member (keeping latitude-longitude fields intact). After shuffling, all statisticsi.e. $\boldsymbol{S}, \boldsymbol{N}, \boldsymbol{S N R}$, and variability and trends in each-were recalculated for each Monte Carlo ensemble. By randomly shuffling each ensemble member, we remove any timedependent (SST-forced) component common among ensemble members while maintaining the distribution of precipitation anomalies in each simulation. In the absence of SST boundary forcing, the signal $S_{t}$ at each time $t$ will tend to zero and the noise $N_{t}$ will tend to a constant with increasing ensemble size $(N \Rightarrow \infty)$. Variability in $\boldsymbol{S}_{\boldsymbol{t}}$ and $N_{t}$ in each Monte Carlo trial therefore arises due to sampling variability across the finite ensemble size $(N=14)$. This Monte Carlo scheme is analogous to standard perturbation techniques (e.g. von Storch and Zwiers 1999).

The simple Monte Carlo scheme used here implicitly assumes that seasonal precipitation anomalies $x_{t n}$ are independent and identically distributed (iid) random variables, and thus stationary. This assumption is appropriate when evaluating variability and trends-i.e. non-stationarity: in order to accept the alternative hypothesis that $S, N$, and $\boldsymbol{S N R}$ are non-stationary, we must reject the null hypothesis that they are stationary. Limited deviations of $x_{\text {tn }}$ from iid are unlikely to substantially bias the results or conclusions presented here, and results area not sensitive to detrending of individual simulations prior to constructing Monte Carlo ensembles. Lastly, it should be noted that a significance threshold of $\alpha=0.05$ is used for all hypothesis tests; results are similar for $\alpha=0.10$ and $\alpha=0.01$.

\section{Mean, variability, and trends in signal, noise, and potential predictability}

Time averaged signal, noise, and potential predictability provide insight into the overall sensitivity of seasonal precipitation to SST boundary forcing, while significant interannual variability or linear trends implies nonstationarity in the dominant physical mechanisms that drive seasonal-to-interannual precipitation anomalies. The mean, variability, and trend in signal and noise characteristics over a given region thus have important implications for hydroclimatic variability and predictability.

\subsection{Twentieth century means}

Figure 1 shows the twentieth century mean signal, noise, and potential predictability $(\bar{S}, \bar{N}$, and $\overline{S N R}$, respectively) of seasonal precipitation anomalies for DJF. $\bar{S}$ and $\overline{S N R}$ are masked by dark hatching where values are not significant at the $\alpha=0.05$ level $\left(\mathrm{H}_{\mathrm{o}}: \bar{\theta} \leq \mathrm{P}_{95}\left\{\bar{\theta}_{\mathrm{MC}}\right\}\right.$, for $\bar{\theta}=\bar{S}$ and $\overline{S N R}) ; \bar{N}$ is statistically significant over less than one percent of the globe and is therefore not masked. The percent of global land and ocean areas exhibiting statistically significant $\bar{S}, \bar{N}$, and $\overline{S N R}$ are summarized in Table 1 .

$\bar{S}$ is highest over the tropics, with peak values exceeding $50 \mathrm{~mm}$ over the central and western tropical Pacific. Regions of moderate $\bar{S}$ occur monsoon regions and regions of Mediterranean climate where seasonal precipitation is strongly influenced by changes in large-scale circulation, including the Mediterranean, western North America, India, eastern Australia, South America, and southern Africa. $\bar{S}$ is statistically significant-i.e. greater than expected by chance-over $91.9 \%$ of the globe $(89.3 \%$ of global land areas). By contrast, $\bar{N}$ is statistically significant over just $0.1 \%$ of the globe $(0.001 \%$ of global land areas). $\bar{N}$ is greatest over the northern Pacific and Atlantic Oceans, northwestern and southern North America, western Europe, and southeastern regions of South America, Africa, and Australia. The spatial distribution of $\bar{N}$ strongly resembles that of the variance of simulated seasonal precipitation (not shown). Similar to $\bar{S}, \overline{S N R}$ is greatest over the tropics and decreases rapidly with latitude. While few regions outside the tropics exhibit values greater than $1.0, \overline{S N R}$ is statistically significant over $91.8 \%$ of the globe $(82.8 \%$ of global land areas). Despite statistical significance, however, low values of $\overline{S N R}$ outside of the tropics indicate that only a small fraction of interannual precipitation variability over these regions is directly attributable to ocean-atmosphere forcing.

At the global scale, the results shown here are consistent with previous estimates of aggregate signal, noise, and potential predictability based on other AGCMs, other time periods, and other methods (e.g. Rowell 1998; Zwiers et al. 2000; Straus et al. 2003; Phillips 2006). It should also be noted that the spatial distribution and statistical significance of $\overline{S N R}$ shown here is nearly identical to results of the well-established ANOVA approach (Zwiers et al. 2000).

\subsection{Interannual variability}

Figure 2 shows standard deviations of signal and noise ( $\sigma_{S}$ and $\sigma_{N}$, respectively) over the twentieth century; values 
(a)

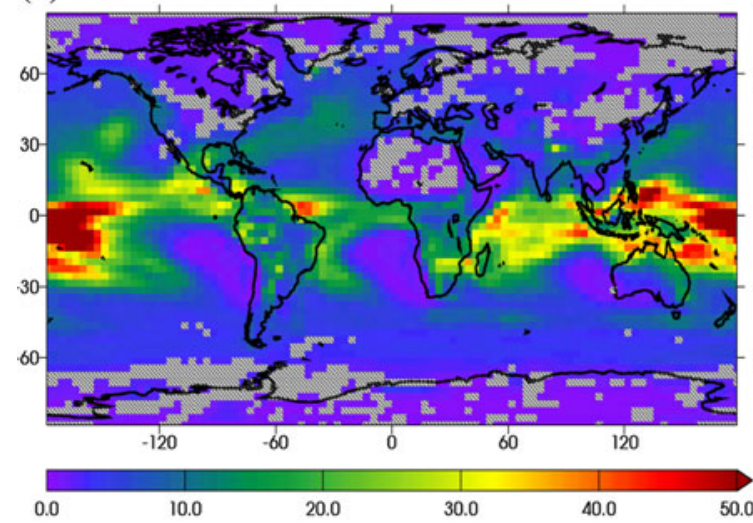

(c)

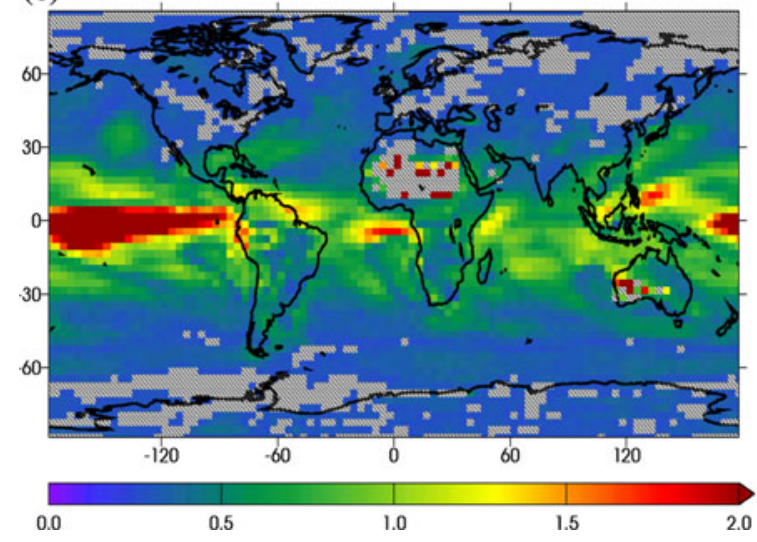

Fig. 1 Mean of 20th century a signal $\bar{S}(\mathrm{~mm})$, b noise $\bar{N}(\mathrm{~mm})$, and c potential predictability $\overline{S N R}$ [-] of seasonal precipitation anomalies for boreal winter (DJF). $\bar{S}$ and $\overline{S N R}$ are masked (dark hatching) where values are not statistically significant at the $\alpha=0.05$ level $\left(\mathrm{H}_{\mathrm{o}}\right.$ :

Table 1 Percentages of global area, land areas, and ocean areas exhibiting statistically significant 20 th century mean signal, noise, and potential predictability $\left(\mathrm{H}_{\mathrm{o}}: \bar{\theta} \leq \mathrm{P}_{95}\left\{\bar{\theta}_{\mathrm{MC}}\right\}\right)$

\begin{tabular}{lrcc}
\hline & Global & Land only & Ocean only \\
\hline Signal $(\bar{S})$ & 91.9 & 83.9 & 94.2 \\
Noise $(\bar{N})$ & 0.1 & 0.0 & 0.2 \\
Potential predictability $(\overline{S N R})$ & 91.8 & 82.8 & 93.9 \\
\hline
\end{tabular}

are masked (dark hatching) where variability is not significant at the $\alpha=0.05$ level $\left(\mathrm{H}_{\mathrm{o}}: \sigma_{\theta} \leq \mathrm{P}_{95}\left\{\sigma_{\theta \mathrm{MC}}\right\}\right.$, for $\sigma_{\theta}=\sigma_{S}$ and $\sigma_{N}$ ), and percent of global land and ocean areas exhibiting statistically significance are summarized in Table 2. Fractions of global area and global and areas exhibit statistically significant variability are summarized in Table 2. The spatial distribution of $\sigma_{S}$ is similar to that of mean signal $\bar{S}$ (Figs. 1a-2a), with significant variability encompassing $89.2 \%$ of the globe $(80.8 \%$ of global land areas). By contrast, $\sigma_{N}$ is significant over just $13.3 \%$ of the globe (18.9\% of global land areas). Regions of significant $\sigma_{N}$ occur over the subtropical Pacific and eastern tropical (b)

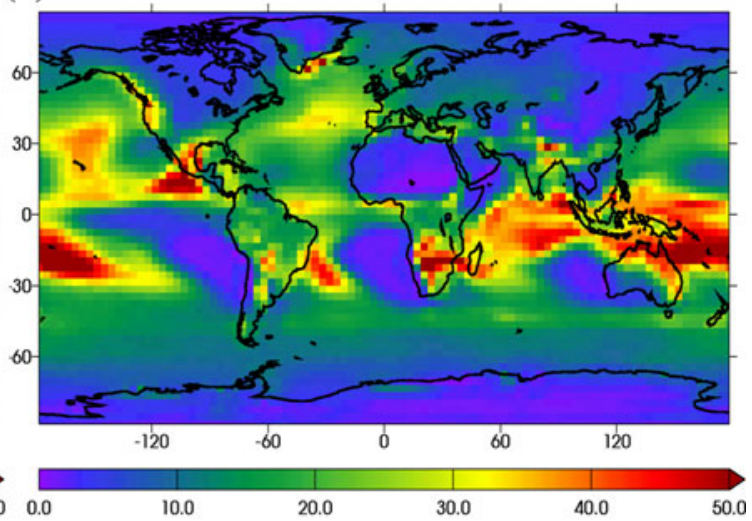

0.0

50.0 $\bar{\theta} \leq \mathrm{P}_{95}\left\{\bar{\theta}_{\mathrm{MC}}\right\} ; \bar{\theta}=\bar{S}$ and $\left.\overline{S N R}\right) . \bar{S}$ is significant over $91.9 \%(83.9 \%)$ of the globe (land only); $\bar{N}$ is significant over $0.1 \%(0.001 \%)$; and $\overline{S N R}$ is significant over $91.8 \%(82.8 \%)$

Atlantic, as well as subtropical areas of Africa, Asia, Australia, and the Middle East; however, the small area of these regions suggests that statistical significance may be spurious. The spatial distribution and statistical significance of $\sigma_{S N R}$ closely resembles that of $\sigma_{S}$ and is therefore not shown; $\sigma_{S N R}$ is statistically significant over $85.9 \%$ of the globe (75.5\% of global land areas). It should be noted that regions of significant $\sigma_{S}$ and $\sigma_{S N R}$ are identical for of $S$ and $\boldsymbol{S N R}$ calculated from detrended ensemble members, indicating that significant interannual variability is independent of linear trends.

\subsection{Linear trends}

Figure 3 shows the linear trends in signal and noise ( $\beta_{S}$ and $\beta_{N}$, respectively) over the twentieth century, masked where trends are not statistically significant at the $\alpha=0.05$ level $\left(\mathrm{H}_{\mathrm{o}}: \beta_{\theta} \leq \mathrm{P}_{95}\left\{\beta_{\theta \mathrm{MC}}\right\}\right.$, for $\beta_{\theta}=\beta_{S}$ and $\left.\beta_{N}\right)$. The percent of global land and ocean areas exhibiting statistically significant $\beta_{S}$ and $\beta_{N}$ are summarized in Table 3. Significant trends in signal encompass $45.0 \%$ of globe $(36.7 \%$ of 
(a)

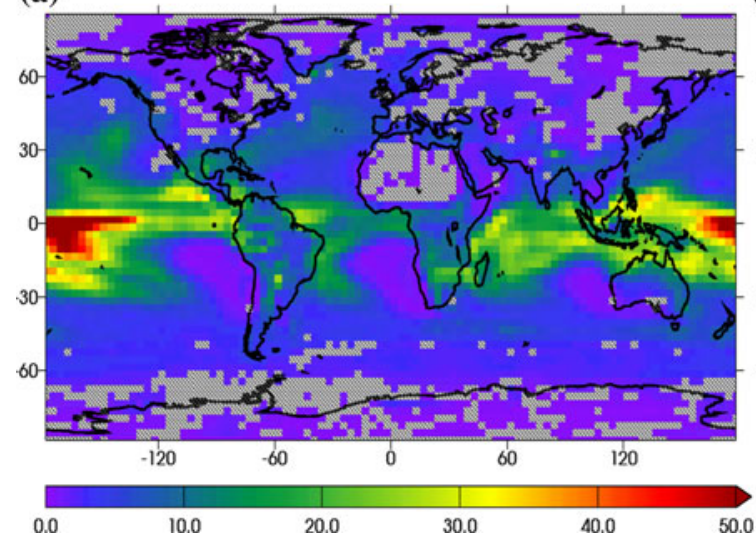

(b)

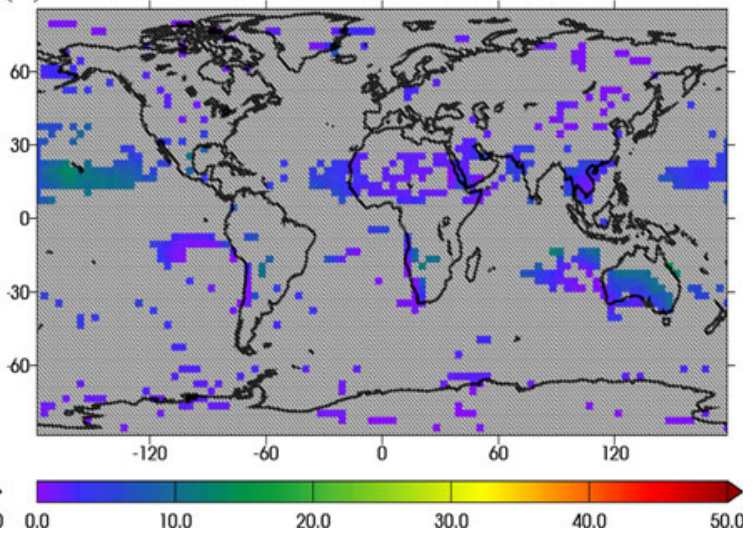

Fig. 2 Interannual standard deviations of a signal $\sigma_{S}(\mathrm{~mm})$ and b noise $\sigma_{N}(\mathrm{~mm})$ of seasonal precipitation anomalies for boreal winter (DJF); values are masked (dark hatching) where not statistically

Table 2 Percentages of global area, land areas, and ocean areas exhibiting statistically significant interannual variability in signal, noise, and potential predictability $\left(\mathrm{H}_{\mathrm{o}}: \sigma_{\theta} \leq \mathrm{P}_{95}\left\{\sigma_{\theta \mathrm{MC}}\right\}\right)$

\begin{tabular}{llll}
\hline & Global & Land only & Ocean only \\
\hline Signal $\left(\sigma_{S}\right)$ & 89.2 & 80.8 & 92.8 \\
Noise $\left(\sigma_{N}\right)$ & 13.3 & 18.9 & 10.9 \\
Potential predictability $\left(\sigma_{S N R}\right)$ & 85.9 & 75.5 & 90.4 \\
\hline
\end{tabular}

global land areas), and are significant at the field scale. The spatial distribution of significant $\beta_{S}$ is similar to that of significant $\sigma_{S}$, but with fewer regions exhibiting statistical significance outside of the tropics. Significant trends are predominately positive, suggesting that the magnitude of SST-forced precipitation variability increased over the twentieth century in the simulations analyzed here. Trends in noise are significant over just $12.2 \%$ of the globe $(4.4 \%$ of global land areas). As for $\sigma_{N}$, regions exhibiting significant trends are mostly small and scattered; however, the spatial distribution of significant trends is not consistent with that of significant variability. Moreover, in contrast to $\beta_{S}, \beta_{N}$ exhibits approximate equal areas of positive and negative trends. The spatial distribution and statistical significance of $\beta_{S N R}$ are similar to those of $\beta_{S}$ and are therefore not shown. $\beta_{S N R}$ is statistically significant over $49.9 \%$ of the globe (43.0\% of global land areas), and is significant at the field scale. As for $\boldsymbol{S}$, significant trends in $S N R$ are predominately positive.

\section{Correlations of signal and noise characteristics with leading modes of SST}

SST-forced signal and potential predictability exhibit statistically significant interannual variability and linear significant at the $\alpha=0.05$ level $\left(\mathrm{H}_{\mathrm{o}}: \sigma_{\theta} \leq \mathrm{P}_{95}\left\{\sigma_{\theta \mathrm{MC}}\right\} ; \sigma_{\theta}=\sigma_{S}\right.$ and $\left.\sigma_{N}\right), \sigma_{S}$ is significant over $89.2 \%(80.8)$ of the globe (land only); $\sigma_{N}$ is significant over $13.3 \%(18.9 \%)$

trends, suggesting that they are non-stationary; variability and trends in chaotic noise are generally within the range of sampling variability over most regions, suggesting that the magnitude of chaotic noise is generally stationary. Previous studies have attributed interannual variability in signal and noise characteristics to variability in SST boundary forcing, specifically ENSO-related tropical SST anomalies. Pegion et al. (2000) compared signal and potential predictability of winter precipitation aggregated over ENSO events to those for all years and found a general increase in both over the tropics and mid-latitudes during ENSO events. Wu and Kirtman (2006) compared the signal, noise, and potential predictability of seasonal precipitation aggregated over warm and cool ENSO years; their results showed significant differences in signal and noise characteristics over much of the globe, while changes in potential predictability were largely confined to the tropics. Other studies have shown similar results for both potential predictability and seasonal forecast and hindcast skill (e.g. Brankovic et al. 1994; Kumar and Hoerling 1998; Zwiers et al. 2000; Hoerling and Kumar 2003; Schlosser and Kirtman 2005; Phillips 2006).

Here we evaluate correlations between signal, noise, and potential predictability, and four dominant modes (EOFs) of twentieth century global SST variability. The leading EOFs of SST variability represent independent patterns of SST variability that account a significant fraction of the total (spatiotemporal) SST variability, and their associated PCs represent the amplitude of an each pattern at a given time. The four leading EOFs and PCs are shown in Fig. 4; EOFs are scaled as the correlation between seasonal SST anomalies and the associated PC, and PCs are standardized to have a mean of zero and unit variance.

The first spatial mode (EOF1; $22.6 \%$ of total variance) is characterized by positive values over most of the globe, 
(a)

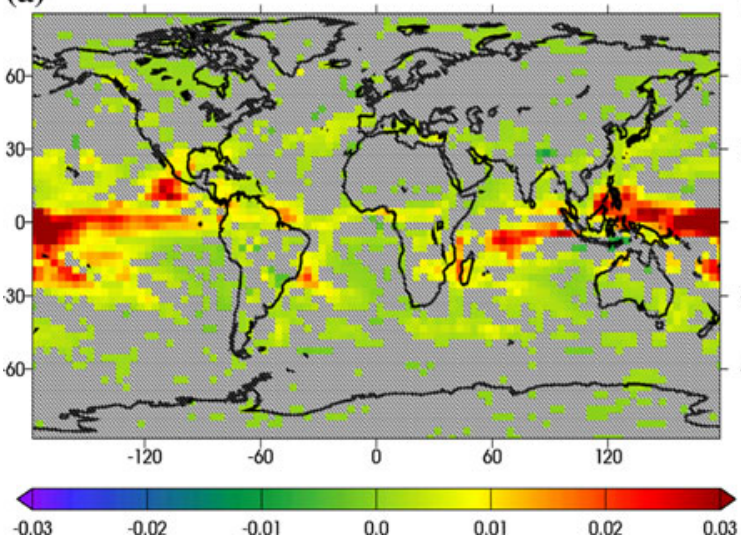

(b)

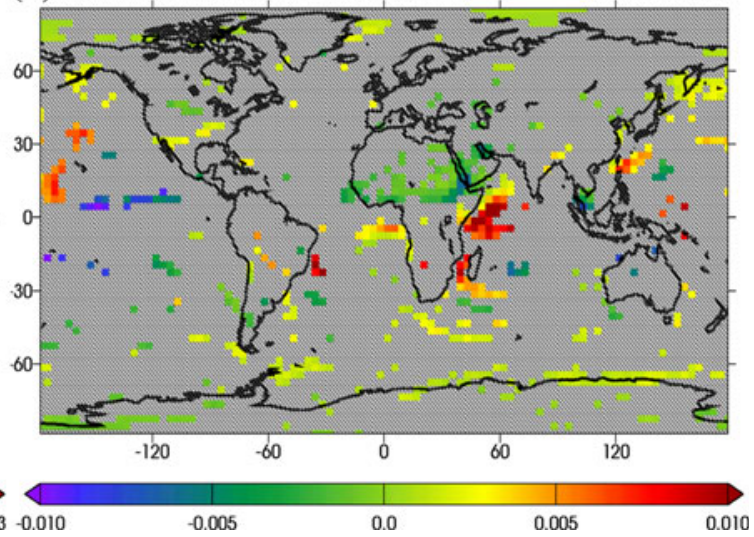

Fig. 3 Linear trends in a signal $\boldsymbol{\beta}_{S}(\mathrm{~mm} / \mathrm{year})$ and $\mathbf{b}$ noise $\boldsymbol{\beta}_{\boldsymbol{N}}$ $(\mathrm{mm} /$ year) of boreal winter (DJF) precipitation anomalies over the 20th century (1902-2001). Values are masked (dark hatching) where

Table 3 Percentages of global area, land areas, and ocean areas exhibiting statistically significant linear trends in signal, noise, and potential predictability $\left(\mathrm{H}_{\mathrm{o}}: \beta_{\theta} \leq \mathrm{P}_{95}\left\{\beta_{\theta \mathrm{MC}}\right\}\right)$

\begin{tabular}{lccl}
\hline & Global & Land only & Ocean only \\
\hline Signal $\left(\beta_{S}\right)$ & 45.0 & 36.7 & 48.5 \\
Noise $\left(\beta_{N}\right)$ & 12.2 & 4.4 & 11.8 \\
Potential predictability $\left(\beta_{S N R}\right)$ & 49.9 & 43.0 & 52.8 \\
\hline
\end{tabular}

with weak negative values over the North Pacific and North Atlantic and along the coast of Antarctica, and the associated PC (PC1) is dominated by a positive linear trend. EOF2 (14.2\% of variance) strongly resembles the canonical ENSO pattern, with strong positive values over the central and eastern tropical Pacific surrounded by strong negative values; PC2 exhibits strong interannual variability and is significantly correlated with SST anomalies over the Nino3.4 region $(r=0.862)$. Peak loadings of EOF3 $(5.9 \%$ of total variance) occur over the North Atlantic, and peak loadings of EOF4 (4.4\% of total variance) occur over the North Pacific; PC3 is inversely correlated with the AMO $(r=-0.426)$ and PC4 is weakly correlated with the PDO $(r=0.200)$. While EOF3 and EOF4 account for relatively small fractions of global SST variability, EOF3 represents more than $20 \%$ of variability over much of the North Atlantic and EOF4 represents more than $15 \%$ of variability over much of the North Pacific. Each of the four leading modes explains a statistically significant fraction of the total SST variability (as per the N-rule test of Preisendorfer 1988).

Correlations between the SST-forced signal and magnitudes of the four leading PCs of seasonal SST variability $\left(r_{S, P C i}\right)$ are shown in Fig. 5, and correlations between the magnitude of chaotic noise and magnitudes of PCs $\left(r_{N, P C i}\right)$ are shown in Fig. 6. Values are masked by dark hatching not statistically significant at the $\alpha=0.05$ level $\left(\mathrm{H}_{\mathrm{o}}\right.$ : $\beta_{\theta} \leq \mathrm{P}_{95}\left\{\beta_{\theta \mathrm{MC}}\right\} ; \beta_{\theta}=\beta_{S}$ and $\left.\beta_{N}\right) . \boldsymbol{\beta}_{S}$ is significant over $45.0 \%$ $(36.7 \%)$ of the globe (land only); $\boldsymbol{\beta}_{N}$ is significant over $12.2 \%(4.4 \%)$

where correlations are not statistically significant at the $\alpha=0.05$ level $\left(\mathrm{H}_{\mathrm{o}}: r_{\theta, P C i} \leq \mathrm{P}_{95}\left\{r_{\theta, P C i \mathrm{MC}}\right\}\right.$, for $r_{\theta, P C i}=$ $r_{S, P C i}$ and $r_{N, P C i}$ and $\left.i=1,2,3,4\right)$; percent of land and ocean areas exhibiting statistically significant correlations are summarized in Table 4.

$\boldsymbol{S}$ is significantly correlated with magnitudes of the four leading PCs over the eastern and central tropical Pacific; outside of this region, significant correlations are widespread only for the magnitude of PC2, which represents ENSO-related SST variability. Significant correlations with PC2 are statistically significant over $34.9 \%$ of the globe (23.5\% of global land areas), including large regions of the Pacific and North Atlantic Oceans, South America, and eastern Australia. Significant correlations are almost entirely positive, indicating that strong SST anomalies in the tropical Pacific are associated with a greater precipitation signal over these regions. The lack of significant correlation over most mid- and high-latitude regions, however, suggests that stronger ENSO events are not directly associated with a stronger precipitation response over these regions, and that non-stationarity of SST-forced signal over these regions is not associated with variability in the magnitude of ENSO-related SST forcing.

Coherent regions of significant correlation between $S$ and the magnitudes of PC1, PC3, and PC4 are largely confined to the tropical Pacific, with few coherent regions of significant correlation over land (Fig. 5; Table 4). Similarly, correlations between $\boldsymbol{S}$ and indices of PDO and AMO are generally weak, particularly over land (not shown). The lack of spatially coherent regions of significant correlation over mid- and high latitudes suggests that statistical significance is spurious and may not be physically meaningful. Results suggest that aside from ENSO, the magnitude of SST-forced signal is not strongly associated with important modes of SST variability. 


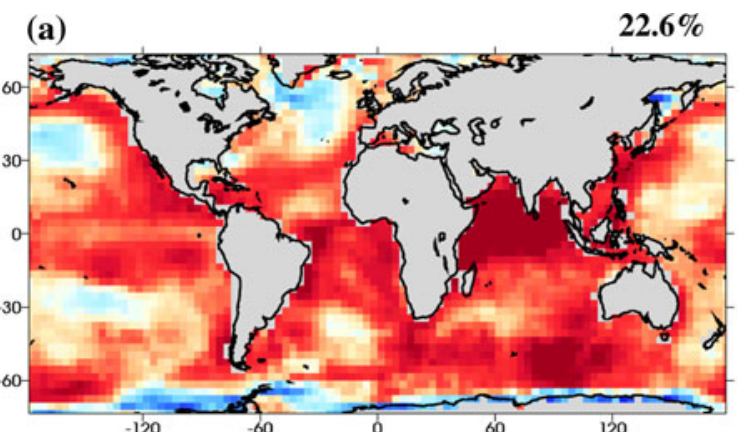

(c)

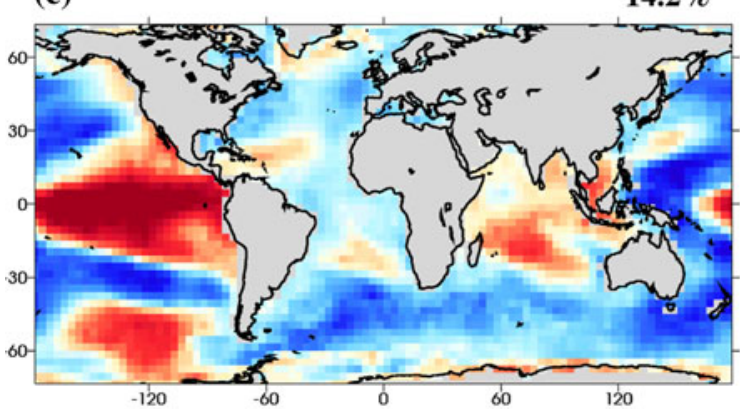

$5.9 \%$

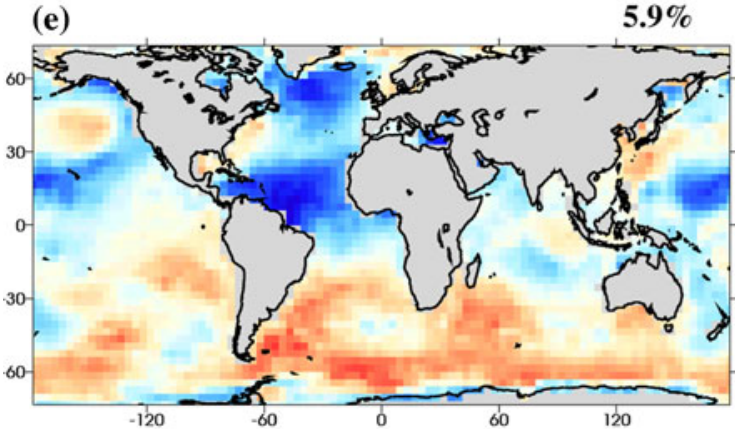

$4.4 \%$

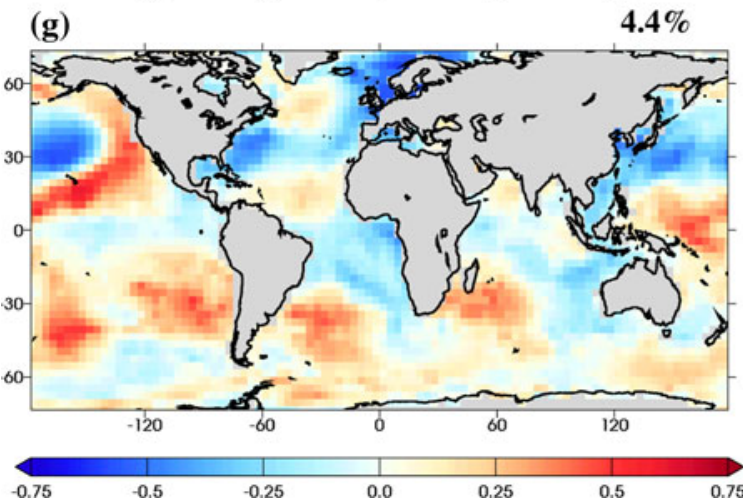

Fig. 4 a, c, e, g Four leading empirical orthogonal functions (EOFs) of global SST variability for boreal winter (DJF) and $\mathbf{b}, \mathbf{d}, \mathbf{f}, \mathbf{h}$ associated principal component time series (PCs). EOFs are scaled as

$N$ is significantly correlated with the magnitudes of PC2 and PC3 over large regions of the tropical Pacific; outside of this region, regions of significant correlation are again small and scattered (Fig. 6; Table 4). The small spatial extent of significant correlation is consistent with lack of significant variability and trends in $N$ over most of the globe and suggests that the magnitude of chaotic noise is

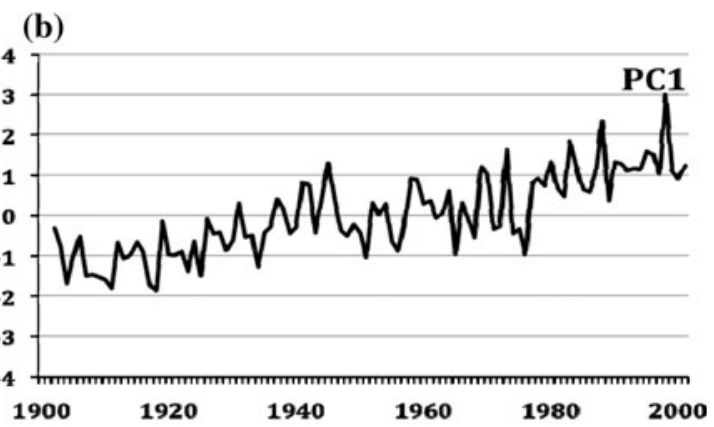

(d)

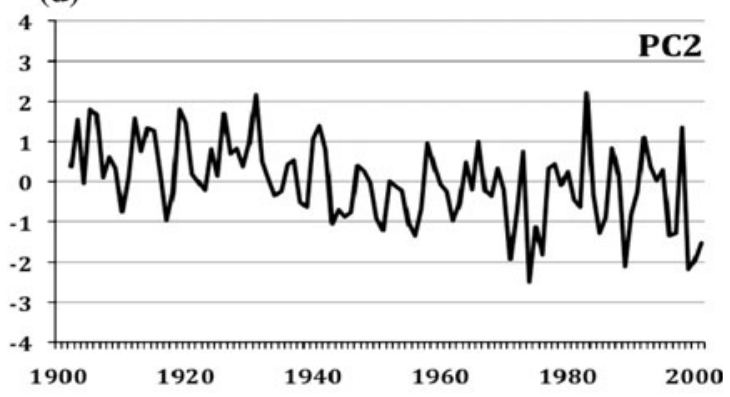

(f)

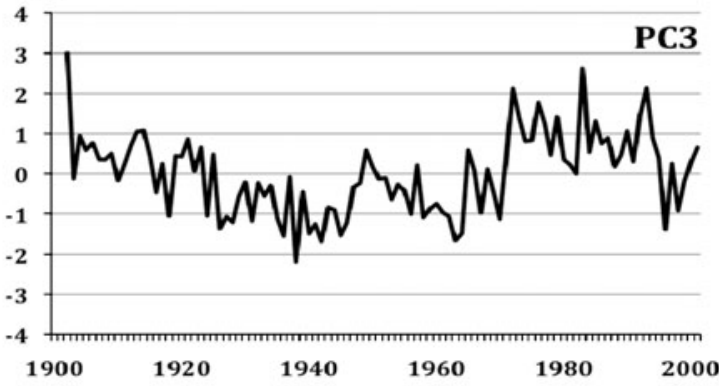

(h)

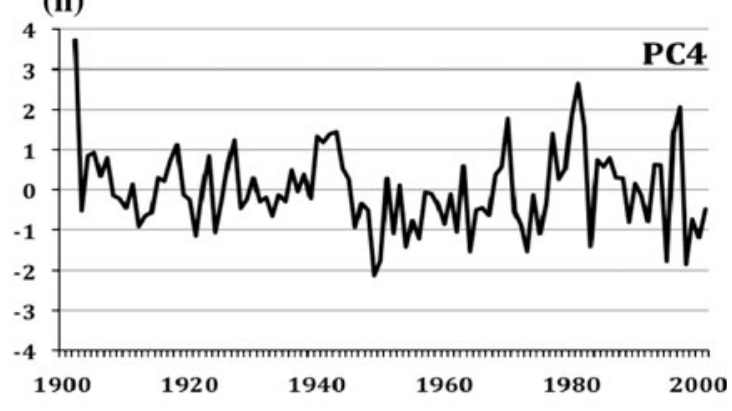

correlations between PCs and seasonal SST anomalies [-]; PCs are scaled to have mean of zero and unit variance [-]. The fraction of variability explained by each mode is shown above each EOF

independent of SST boundary conditions. Similar to $S$, correlations between $N$ and indices of PDO and AMO are not statistically significant over most of the globe (not shown). The spatial distribution and statistical significance of correlations between $\boldsymbol{S N R}$ and each of the indices evaluated here are similar to those for $\boldsymbol{S}$ and are therefore not shown. 
(a)

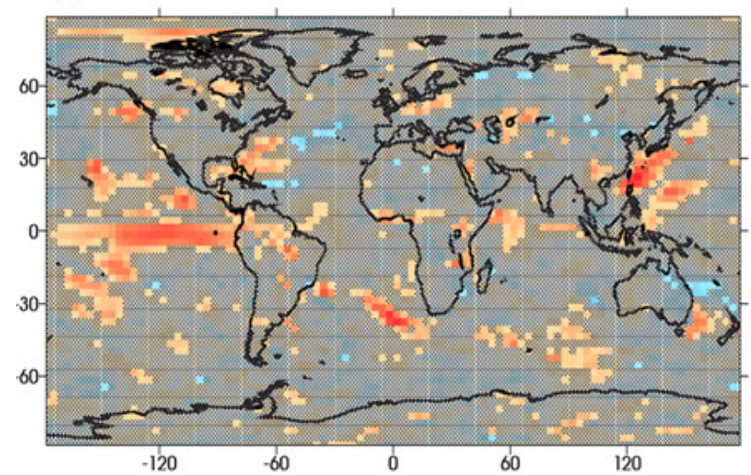

(c)

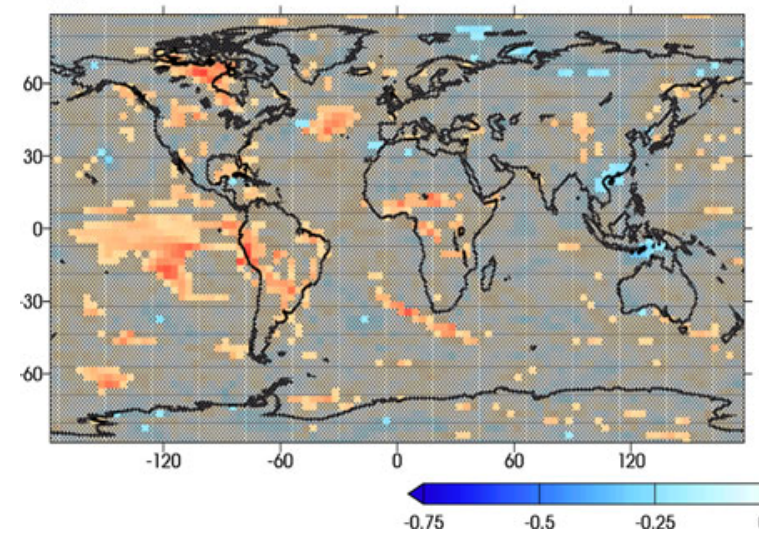

(b)

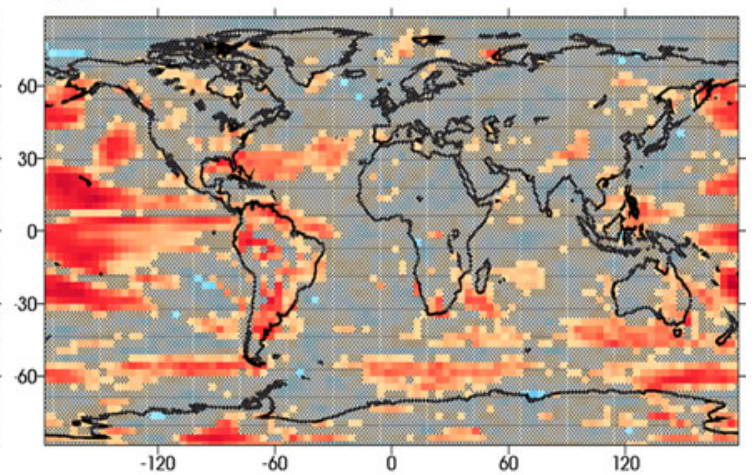

(d)

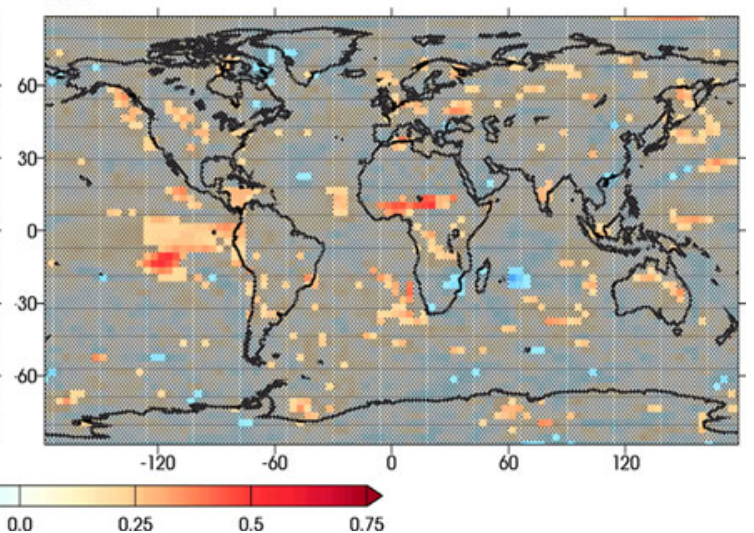

Fig. 5 Temporal correlations $r_{s, P C i}[-]$ between signal $\boldsymbol{S}$ and the four leading PCs of boreal winter (DJF) SST variability. Values are hatched where $r_{s, P C i}$ is not statistically significant at the $\alpha=0.05$ level $\left(\mathrm{H}_{\mathrm{o}}: r_{S, P C i} \leq \mathrm{P}_{95}\left\{r_{S, P C i \mathrm{MC}}\right\}\right)$. The fraction of global area

\section{Discussion}

Recent studies have identified temporal variability and trends in actual and potential predictability of seasonal climate anomalies, suggesting that the physical mechanisms - and thus predictability — of seasonal anomalies are non-stationary. Using a simple Monte Carlo approach, we show that interannual variability and long-term trends in SST-forced signal and potential predictability of seasonal precipitation anomalies in an ensemble of twentieth century AGCM simulations are greater than expected by chance over much of the globe, while variability and trends in chaotic noise are within the range of sampling variability over most regions.

Because $S$ and $S N R$ represent the atmosphere's response to SST boundary conditions, and because SST vary in time, we look to variability in SST themselves as the most likely driver of variability in signal and potential predictability. Previous studies have shown a widespread increase in $S$ and $\boldsymbol{S N R}$, as well as forecast skill, during ENSO events compared to ENSO-neutral periods. Similarly, our analysis demonstrates that interannual variability in $\boldsymbol{S}$ and $\boldsymbol{S N R}$ over exhibiting significant correlation is shown above each panel; the fraction of land areas exhibiting significant correlation is shown in parentheses

more than $35 \%$ of the globe is significantly correlated with the magnitude of PC2 of global SST, which represents the global SST signature of ENSO. Moreover, peak values of the means and standard deviations in $\boldsymbol{S}$ and $\boldsymbol{S N R}$ (Figs. 1-2) and the occurrence of statistically significant linear trends (Fig. 3) largely coincide with regions over which $S$ and SNR are significantly correlated with the magnitude of PC2. Comparison of Fig. 2 with Figs. 5-6, however, shows that the spatial extent of statistically significant variability in SST-forced signal $S$ is substantially greater than the extent of significant correlation with PC2. Moreover, though statistically significant, correlation with PC2 generally explains only a fraction of interannual variability in $S$ and $S N R$, suggesting that only a small fraction of variability is directly associated with ENSO.

To assess the influence of non-ENSO SST variability on signal and noise characteristics, additional correlation analysis was carried out with respect to additional principal components of seasonal SST and indices of PDO and AMO variability. Correlations between $S, N$, and $S N R$ and nonENSO PCs are generally weak; regions of statistically significant correlation are small and scattered, particularly 

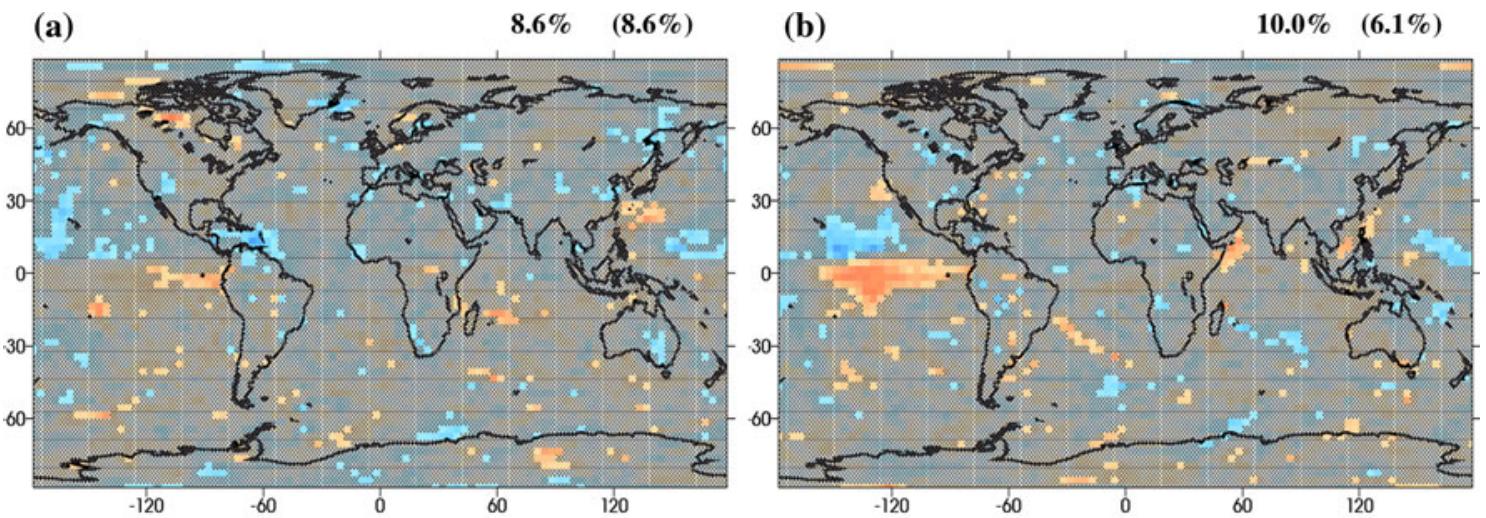

(c)

$11.2 \%(11.0 \%)$

(d)

$11.6 \%(16.1 \%)$

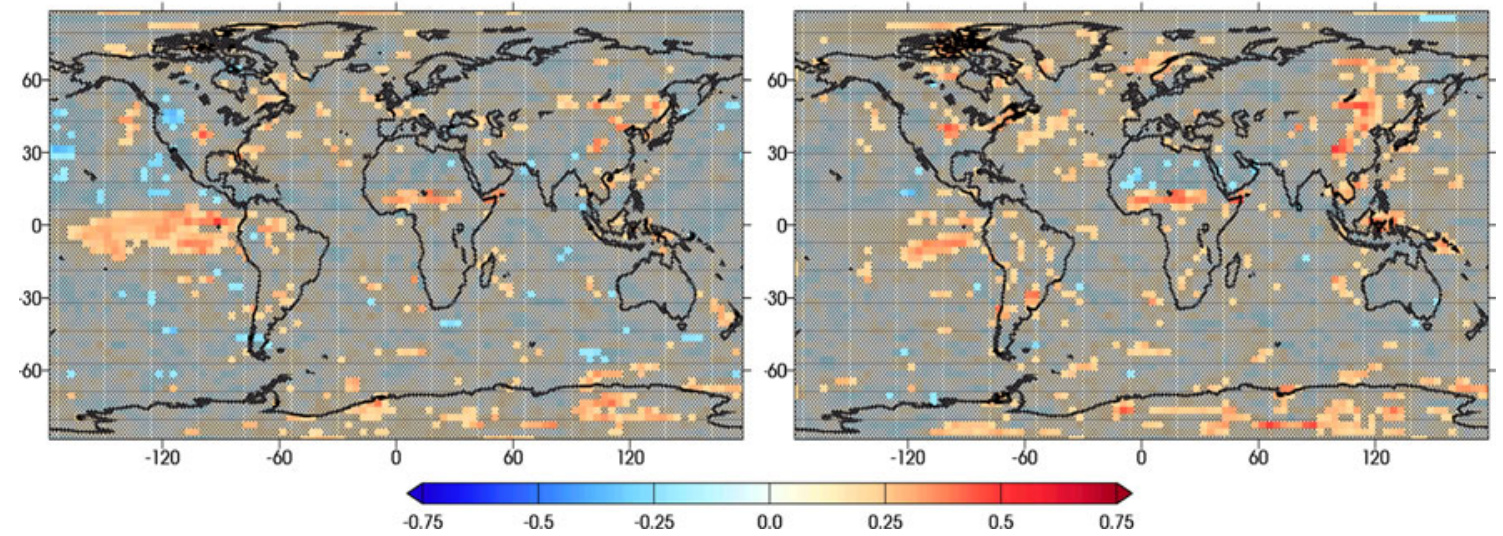

Fig. 6 Temporal correlations $r_{N, P C i}[-]$ between noise $\boldsymbol{N}$ and the four leading PCs of boreal winter (DJF) SST variability. Values are hatched where $r_{N, P C i}$ is not statistically significant at the $\alpha=0.05$ level $\left(\mathrm{H}_{\mathrm{o}}: r_{N, P C i} \leq \mathrm{P}_{95}\left\{r_{N, P C i \mathrm{MC}}\right\}\right)$. The fraction of global area

exhibiting significant correlation is shown above each panel; the fraction of land areas exhibiting significant correlation is shown in parentheses

Table 4 Percentages of global area (land only) [ocean only] exhibiting statistically significant correlation between signal, noise, and potential predictability and four leading PCs of Global SST variability $\left(\mathrm{H}_{\mathrm{o}}: r_{\theta, P C i} \leq \mathrm{P}_{95}\left\{r_{\theta, P C i \mathrm{MC}}\right\}\right)$

\begin{tabular}{|c|c|c|c|c|}
\hline & PC1 & PC2 & PC3 & PC4 \\
\hline \multirow[t]{2}{*}{ Signal $\left(r_{S, P C i}\right)$} & $16.6(12.8)$ & $34.9(23.5)$ & $13.7(16.1)$ & $10.4(12.8)$ \\
\hline & [18.2] & [39.7] & {$[12.8]$} & {$[9.4]$} \\
\hline \multirow[t]{2}{*}{ Noise $\left(r_{N, P C i}\right)$} & $8.6(8.6)$ & $10.0(6.1)$ & $11.2(11.0)$ & $11.6(16.1)$ \\
\hline & [8.6] & [11.6] & [11.3] & [9.7] \\
\hline \multirow[t]{2}{*}{ Potential Predictability $\left(r_{S N R, P C i}\right)$} & $17.5(14.3)$ & $33.7(23.5)$ & $11.9(13.0)$ & $6.8(8.3)$ \\
\hline & [18.8] & [37.9] & [11.4] & [6.2] \\
\hline
\end{tabular}

over land, suggesting that significant correlations are spurious and are not physically meaningful. The lack of significant correlation between $\boldsymbol{S}$ and $\boldsymbol{S N R}$ and indices of PDO and AMO (not shown) again suggest that nonstationarity of simulated signal and potential predictability is not significantly associated with extratropical (nonENSO) modes of SST variability at the seasonal-to-interannual timescales considered here.

Significant linear trends in $\boldsymbol{S}$ and $\boldsymbol{S N R}$ (Fig. 3) suggest that variability in signal and potential predictability over these regions is driven by a forcing mechanism that also exhibits a significant linear trend. Consistent with PC1 of global SST, seasonal SST exhibit a statistically significant positive trend over most of the globe (not shown), with the exception of the tropical Pacific; however, the amplitude of tropical Pacific SST anomalies exhibits a significant positive trend over the latter half of the twentieth century (e.g. Torrence and Webster 1999; Mokhov et al. 2004). Positive trends in the amplitude of PC2 (not shown) suggest an increase in the magnitude of ENSO-related tropical SST forcing; the sign and spatial distribution of significant trends in $\boldsymbol{S}$ and $\boldsymbol{S N R}$ are thus consistent with the significant 
correlation of $\boldsymbol{S}$ and $\boldsymbol{S N R}$ over these regions with the magnitude of PC2. While not conclusive, the strong correspondence between regions that exhibit significant correlations and those that exhibit significant trends suggests that trends in signal and potential predictability are predominately driven by trends in ENSO-related SST forcing.

The magnitude of SST-forced signal $S$ and potential predictability $\boldsymbol{S N R}$ exhibit statistically significant interannual variability and trends over more than $85 \%$ of the globe, while variability in $\boldsymbol{S}$ and $\boldsymbol{S N R}$ is significantly associated dominant modes of SST variability over less than half of this area. These results suggest that while SST boundary forcing is an important driver of precipitation variability over much of the globe, including non-stationarity of seasonal precipitation characteristics (Fig. 1; Stockdale et al. 1998; Koster et al. 2000; Schubert et al. 2004; Barnston et al. 2005; Saha et al. 2006; Schubert et al. 2007; Livezey and Timofeyeva 2008), SST are not a dominant driver of non-stationarity in the SST-forced signal and potential predictability of simulated seasonal precipitation anomalies over most of the globe in the simulations analyzed here. Previous analysis by Schubert et al. (2008) suggests that land-atmosphere feedbacks influence temporal variability of the signal and noise characteristics of seasonal precipitation anomalies over some regions and seasons. Other studies suggest that some atmospheric states are inherently more predictable than others; (e.g. Palmer 2000; Collins and Allen 2002; Reichlerand and Roads 2003), implying that chaotic atmospheric dynamics contribute to variability in signal and noise characteristics on a range of timescales. Further analysis of such mechanisms is beyond the scope of the current analysis.

It should be noted that results based on idealized numerical experiments such as those analyzed here can not be directly confirmed by observations-indeed, the ability to perform such idealized experiments is a valuable property of numerical models. As noted above, the simulations analyzed here reproduce many important features of observed seasonal precipitation anomalies, including the magnitude and spatial distribution of the seasonal precipitation response to tropical SST forcing. However, it is possible that the model used here does not accurately represent some potentially predictable modes of precipitation variability, for example the precipitation response to extratropical SST forcing, which is difficult to validate with respect to observations. Multi-model intercomparison of variability and trends in the signal and noise characteristics of seasonal precipitation anomalies in other AGCMs is necessary to assess the model dependence of the results presented here.

As noted in Sect. 2, the interpolation scheme used to reconstruct HadISST global SST fields causes spatial and temporal smoothing over data-sparse periods and regions, resulting in artificially low SST variance during the early twentieth century and thus artificial (positive) trends in the amplitude and variance of SST. To the extent that they are influenced by variations in SST boundary forcing, temporal variability and trends in the signal and potential predictability of the real atmosphere are thus likely differ in magnitude and timing from those in the simulations analyzed here. However, potential biases in the HadISST forcing dataset do not detract from our primary conclusion-viz. that non-stationarity in the SST-forced signal and potential predictability of seasonal precipitation anomalies throughout the tropics is associated ENSOrelated SST variability, while non-stationarity over most mid- and high-latitude regions is not associated with the dominant modes of large-scale SST variability.

Lastly, it should be noted that the current analysis focuses on non-stationarity of the SST-forced signal, chaotic noise, and potential predictability of seasonal precipitation anomalies, but does not address non-stationarity of the climate itself. Changes in atmospheric composition and radiative properties are likely to impact internal atmospheric dynamics and moist atmospheric processes, large-scale circulation, and ocean-atmosphere coupling, which in turn are likely to affect the signal and noise characteristics of seasonal-to-interannual precipitation variability. While the simulations analyzed here incorporate the observed twentieth century global warming signal as captured by the HadISST forcing dataset, further analysis is needed to understand the potential impacts of climate change on signal and noise characteristics of seasonal precipitation anomalies.

\section{Conclusions}

The global climate system is inherently non-stationary (e.g. IPCC 2007). Hydroclimatic variability-including droughts and floods-are some of the costliest of natural disasters, and non-stationarity of precipitation and drought characteristics has important implications for decision makers in a broad range of contexts (e.g. Milly et al. 2008). Current long-range forecast systems are largely based on the long (compared to weather systems) timescales of SST anomalies and their influence on large-scale circulation and moisture transport. The signal and noise characteristics of seasonal forecast systems provide insight into the uncertainty of seasonal forecasts. Our results demonstrate that the signal and potential predictability of seasonal precipitation anomalies during boreal winter are non-stationary over more than $85 \%$ of the globe, but that the observed non-stationarity is associated with ENSO-related SST variability over less than $35 \%$ of the globe. Continued 
analysis of the signal and noise characteristics of seasonalto-interannual climate variability is needed to understand the physical mechanisms and predictability of seasonal climate, to improve the skill of seasonal forecast systems, and to improve the application of seasonal forecast information by decision makers.

Open Access This article is distributed under the terms of the Creative Commons Attribution Noncommercial License which permits any noncommercial use, distribution, and reproduction in any medium, provided the original author(s) and source are credited.

\section{References}

Adler RF, Huffman GJ, Chang A, Ferraro R, Xie P, Janowiak J, Rudolf B, Schneider U, Curtis S, Bolvin D, Gruber A, Susskind J, Arkin P (2003) The version 2 global precipitation climatology project (GPCP) monthly precipitation analysis (1979-present). J Hydrometeorol 4(6):1147-1167

Bacmeister JT, Pegion PJ, Schubert SD, Suarez MJ (2000) Atlas of seasonal means simulated by the NSIPP-1 atmospheric GCM. NASA Technical Memo-2000-104606, vol 17, pp 194

Barnston AG, Kumar A, Goddard L, Hoerling MP (2005) Improving seasonal prediction practices through attribution of climate variability. Bull Am Meteorol Soc 86(1):59-71

Brankovic C, Palmer TN, Ferranti L (1994) Predictability of seasonal atmospheric variations. J Clim 7(2):217-237

Cayan DR, Redmond KT, Riddle LG (1999) ENSO and hydrologic extremes in the Western United States. J Clim 12(9):2881-2893

Chervin RM (1986) Interannual variability and seasonal climate predictability. J Atmospheric Sci 43(3):233-251

Collins M, Allen MR (2002) Assessing the relative roles of initial and boundary conditions in interannual to decadal climate predictability. J Clim 15(21):3104-3109

Enfield DB, Mestas-Nunes AM, Trimble PJ (2001) The Atlantic multidecadal oscillation and its relation to rainfall and river flows in the Continental US. Geophys Res Lett 28(10):2077-2080

Folland C, Shukla J, Kinter J, Rodwell M (2002) The climate of the twentieth century project. CLIVAR Exch 7(2):37-39

Garbrecht JD, Schneider JM, Brown GO (2006) Decade-long precipitation variations and water resources management. Climate variations, climate change, and water resources engineering. American Society of Civil Engineers, Reston

Gershunov A, Barnett TP (1998) Interdecadal modulation of ENSO teleconnections. Bull Am Meteorol Soc 79(12):2715-2725

Grimm AM, Sahai AK, Ropelewski CF (2006) Interdecadal variations in AGCM simulation skills. J Clim 19(14):3406-3419

Hamlet AF, Lettenmaier DP (1999) Columbia river streamflow forecasting based on ENSO and PDO climate signals. J Water Resour Planning Manag ASCE 125(6):333-341

Hoerling MP, Kumar A (2003) The perfect ocean for drought. Science 299(5607):691-694

IPCC (Intergovernmental Panel on Climate Change) (2007) Climate Change 2007: Impacts, adaptation, and vulnerability. In: Parry ML, Canziani OF, Linden JP, Hanson CE (eds) Contribution of working group II to the fourth assessment report of the intergovernmental panel on climate change, Cambridge University Press, Cambridge

Kang IS, Jin EK, An KH (2006) Secular increase of seasonal predictability for the 20th century. Geophys Res Lett 33(2): Article no. L02703
Keyantash J, Dracup JA (2002) The quantification of drought: an evaluation of drought indices. Bull Am Meteorol Soc 83(8):1167-1180

Koster RD, Suarez MJ (1996) The influence of land surface moisture retention on precipitation statistics. J Clim 9(10):2551-2567

Koster RD, Suarez MJ, Heiser M (2000) Variance and predictability of precipitation at seasonal-to-interannual timescales. J Hydrometeorol 1(1):26-46

Kumar A, Hoerling MP (1998) Annual cycle of pacific north american seasonal predictability associated with different phases of ENSO. J Clim 11(12):3295-3308

Livezey RE, Chen WY (1983) Statistical field significance and its determination by Monte Carlo techniques. Mon Weather Rev 111(1):46-59

Livezey RE, Timofeyeva MM (2008) The first decade of long-lead US seasonal forecasts: insights from a skill analysis. Bull Am Meteorol Soc 89(6):843-854

Lorenz EN (1963) Deterministic Nonperiodic Flow. J Atmospheric Sci 20(2):130-141

Madden RA (1976) Estimates of natural variability of time-averaged sea level pressure. Mon Weather Rev 104(7):942-952

Mantua NJ, Hare SR (2002) The Pacific decadal oscillation. J Oceanogr 58(1):35-44

McCabe GJ, Dettinger M (1999) Decadal variations in the strength of ENSO teleconnections with precipitation in the Western United States. Int J Climatol 19(13):1399-1410

Milly PCD, Betancourt J, Falkenmark M, Hirsch RM, Kundzewicz ZW, Lettenmaier DP, Stouffer RJ (2008) Stationarity is dead: whither water management? Science 319(5863):573-574

Mokhov II, Khvorostyanov DV, Eliseev AV (2004) Decadal and longer term changes in El Nino-Southern oscillation characteristics. Int J Climatol 24(4):401-414

Nakaegawa T, Kanamitsu M, Smith TM (2004) Interdecadal trend of precipitation skill in an ensemble of AMIP-type experiment. J Clim 17(14):2881-2889

Palmer TN (2000) Predicting uncertainty in forecasts of weather and climate. Rep Prog Phys 63(2):71-116

Pegion PJ, Schubert SD, Suarez MJ (2000) An assessment of the predictability of northern winter seasonal means with the NSIPP1 AGCM. NASA Technical Memo-2000-104606, vol 18, pp 124

Peng PT, Kumar A, Barnston AG, Goddard L (2000) Simulation skills of the SST-forced global climate variability of the NCEP-MRF9 and the Scripps-MPI ECHAM3 models. J Clim 13(20):36573679

Phillips TJ (2006) Reproducibility of seasonal land surface climate. J Hydrometeorol 7(2):114-136

Preisendorfer RW (1988) Principal component analysis in meteorology and oceanography. Elsevier Academic Press, New York

Quan X, Hoerling M, Whitaker J, Bates G, Xu T (2006) Diagnosing souces of US seasonal forecast skill. J Clim 19(7):3279-3293

Randel WJ, Wu F, Oltmans SJ, Rosenlof K, Nedoluha GE (2004) Interannual changes of stratospheric water vapor and correlations with tropical tropopause temperatures. J Atmospheric Sci 61(17):2133-2148

Rayner NA, Parker DE, Horton EB, Folland CK, Alexander LV, Rowell DP, Kent EC, Kaplan A (2003) Global analyses of sea surface temperature, sea ice, and night marine air temperature since the late nineteenth century. J Geophys Res Atmospheres 108(D14): Article no. 4407

Reichlerand TJ, Roads Jo (2003) The role of boundary and initial conditions for dynamical seasonal predictability. Nonlinear Processes Geophys 10(3):211-232

Rowell DP (1998) Assessing potential seasonal predictability with an ensemble of multidecadal GCM simulations. J Clim 11(2):109_ 120 
Saenz J, Zubillaga J, Fernandez J (2002) Geophysical data analysis using Python. Comput Geosci 28(4):457-465

Saha S, Nadiga S, Thiaw C, Wang J, Wang W, Zhang Q, Van HM, den Dool HL, Pan S, Moorthi D, Behringer D, Stokes M, Pena S, Lord G, White W, Ebisuzaki P, Peng P, Xie P (2006) The NCEP climate forecast system. J Clim 19(15):3483-3517

Santer BD, Mears C, Wentz FJ, Taylor KE, Gleckler PJ, Wigley TML, Barnett TP, Boyle JS, Bruggemann W, Gillett NP, Klein SA, Meehl GA, Nozawa T, Pierce DW, Stott PA, Washington MW, Wehner MF (2006) Identification of human-induced changes in atmospheric moisture content. Proc Natl Acad Sci USA 104(39):15248-15253

Schlosser CA, Kirtman BP (2005) Predictable skill and its association to sea-surface temperature variations in an ensemble of climate simulations. J Geophys Res Atmospheres 110(D19): Article no. D19107

Schubert SD, Suarez MJ, Pegion PJ, Koster RD, Bacmeister JT (2004) On the causes of the 1930s Dust Bowl. Science 303(5665): 1855-1859

Schubert SD, Koster RD, Hoerling MP, Seager R, Lettenmaier D, Kumar A, Gutzler D (2007) Predicting drought on seasonalto-decadal timescales. Bull Am Meteorol Soc 88(10):1625-1630

Schubert SD, Suarez MJ, Pegion PJ, Koster RD, Bacmeister JT (2008) Potential predictability of long-term drought and pluvial conditions in the US great plains. J Clim 21(4):802-816

Seager R, Kushnir Y, Herweijer C, Naik N, Velez J (2005) Modeling of tropical forcing of persistent droughts and pluvials over Western North America: 1856-2000. J Clim 18(19):4065-4088

Shukla J (1983) Comments on natural variability and predictability. Mon Weather Rev 111(3):581-585

Shukla J (1998) Predictability in the midst of chaos: a scientific basis for climate forecasting. Science 282(5389):728-731

Shukla J, Anderson J, Baumhefner D, Brankovic C, Chang Y, Kalnay E, Marx L, Palmer T, Paolino D, Ploshay J, Schubert S, Straus D, Suarez M, Tribbia J (2000) Dynamical seasonal prediction. Bull Am Meteorol Soc 81(11):2593-2606
Stockdale TN, Anderson DLT, Alves JOS, Balmaseda MA (1998) Global seasonal rainfall forecasts using a coupled oceanatmosphere model. Nature 392(6674):370-373

Straus D, Shukla J, Paulino D, Schubert S, Suarez M, Pegion P, Kumar A (2003) Predictability of the seasonal mean atmospheric circulation during autumn, winter, and spring. J Clim 16(22):3629-3649

Suarez MJ, Takacs LL (1995) Documentation of the Aires/GEOS Dynamical Core Version 2. NASA Technical Memo-1995104606, vol 10, pp 56

Torrence C, Webster PJ (1999) Interdecadal changes in the ENSOMonsoon system. J Clim 12(8):2679-2690

von Storch H, Zwiers FW (1999) Statistical analysis in climate research. Cambridge University Press, Cambridge

Wall ME, Rechtsteiner A, Rocha LM (2003) Singular value decomposition and principal component analysis. In: Berrar DP, Dubitzky W, Granzow M (eds) A practical approach to microarray data analysis. Kluwer, Norwell

Wilhite DE, Buchanan-Smith M (2005) Drought as hazard: understanding the natural and social context. In: Wilhite DE (ed) Drought and water crises: science, technology, and management issues. Taylor and Francis Group, New York

Wu RG, Kirtman BP (2006) Changes in spread and predictability associated with ENSO in an ensemble of coupled GCM simulations. J Clim 19(17):4378-4396

Zheng X, Nakamura H, Renwick JA (2000) Potential predictability of seasonal means based on monthly time series of meteorological variables. J Clim 13(7):2591-2604

Zwiers FW (1996) Interannual variability and predictability in an ensemble of AMIP climate simulations conducted with the CCC GCM2. Clim Dyn 12(12):825-847

Zwiers FW, Wang XL, Sheng J (2000) Effects of specifying bottom boundary conditions in an ensemble of atmospheric GCM simulations. J Geophys Res Atmospheres 105(D6):7295-7315 